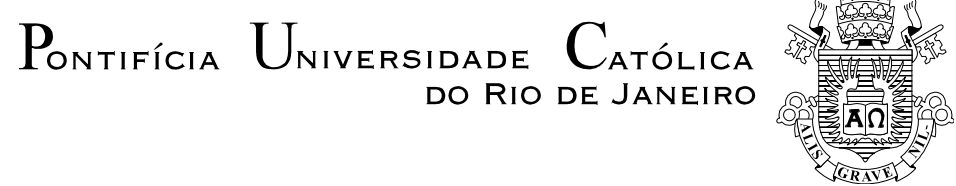

Mayara Alves Maia

Uma investigação reflexiva sobre uma abordagem de ensino-aprendizagem baseada em gêneros discursivos: o caso de turma 601

Dissertação de Mestrado

Dissertação apresentada como requisito parcial para obtenção do grau de Mestre pelo Programa de Pós-graduação em Letras do Departamento de Letras da PUC-Rio.

Orientadora: Profa. Barbara Jane Wilcox Hemais 


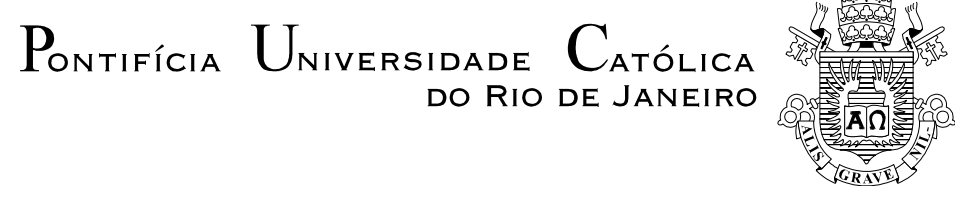

Mayara Alves Maia

\title{
Uma investigação reflexiva sobre uma abordagem de ensino-aprendizagem baseada em gêneros discursivos: o caso de turma 601
}

\begin{abstract}
Dissertação apresentada como requisito parcial para obtenção do grau de Mestre pelo programa de Pós-Graduação em Letras do Departamento de Letras do Centro de Teologia e Ciências Humanas da PUC-Rio. Aprovada pela Comissão Examinadora abaixo assinada.
\end{abstract}

Profa. Barbara Jane Wilcox Hemais

Orientadora

Departamento de Letras - PUC-Rio

Prof. Inés Kayon de Miller

Departamento de Letras - PUC-Rio

Profa. Isabel Cristina Rangel Moraes Bezerra

UERJ

Profa. Denise Berruezo Portinari

Coordenadora Setorial do Centro de Teologia

e Ciências Humanas - PUC-Rio

Rio de Janeiro, 12 de setembro de 2011 
Todos os direitos reservados. É proibida a reprodução total ou parcial do trabalho sem autorização da universidade, da autora e da orientadora.

Mayara Alves Maia

Graduou-se e se licenciou em Letras, Português e Inglês pela UFRJ, estagiando no CAP-UFRJ. Especialista em Linguística Aplicada ao Ensino de Inglês como Língua Estrangeira pela UERJ. Lecionou inglês no CNA, CLACUFRJ e SEERJ. Atuou como orientadora pedagógica no Yázigi. Atualmente, faz parte do quadro de professores de inglês da SME-RJ, Colégio Pedro II e da Cultura Inglesa. No ano de 2009, ingressou no Mestrado em estudos da Linguagem da PUC-Rio com ênfase nas áreas de gêneros discursivos e linguística aplicada.

Ficha Catalográfica

Maia, Mayara Alves

Uma investigação reflexiva sobre uma abordagem de ensino-aprendizagem baseada em gêneros discursivos: o caso de turma 601 / Mayara Alves Maia ; orientadora: Barbara Jane Wilcox Hemais. - 2011.

97 f. : il. (color.) ; $30 \mathrm{~cm}$

Dissertação (mestrado)-Pontifícia Universidade Católica do Rio de Janeiro, Departamento de Letras, 2011. Inclui bibliografia

1. Letras - Teses. 2. Ensino e aprendizagem de inglês. 3. Gêneros discursivos. 4. EJA - Educação de jovens e adultos. 5. Pesquisa-ação. I. Maia, Mayara Alves. II. Pontifícia Universidade Católica do Rio de Janeiro. Departamento de Letras. III. Título. 


\section{Agradecimentos}

A Deus, pela força.

A minha mãe, Joisiney Alves Maia, pela vida e amor.

Ao meu pai, Nelson Maia, pelo incentivo e amor incondicional.

A bolsa de isenção PUC-Rio, sem a qual teria sido impossível realizar o Mestrado.

A professora Barbara Jane Wilcox Hemais por ter aceitado ser minha orientadora e por toda compreensão e paciência que me dedicou.

As professoras Inês Kayon Miller, Isabel Cristina Rangel Moraes Bezerra e Beatriz Barreto por aceitarem gentilmente participar da minha banca.

A Chiquinha e Daniele, secretárias da pós, pelo carinho e atenção a todos os meus pedidos.

A todos os alunos da turma 601 que me ajudaram na pesquisa.

A todos os meus prestativos e incentivadores amigos. 


\section{Resumo}

Maia, Mayara Alves; Hemais, Barbara Jane Wilcox. Uma investigação reflexiva sobre uma abordagem de ensino-aprendizagem baseada em gêneros discursivos: o caso da turma 601. Rio de Janeiro, 2011. 97p. Dissertação de Mestrado - Departamento de Letras, Pontifícia Universidade Católica do Rio de Janeiro.

A pesquisa aqui apresentada tem por objetivo observar o desempenho de aprendizes em uma instituição pública quando é adotada uma pedagogia baseada em uma abordagem pautada em gêneros discursivos. Os alunos em questão são do $2^{\circ}$ ciclo do ensino fundamental, na modalidade EJA (Educação para Jovens e Adultos) de uma escola pública do Estado do Rio de Janeiro, e na época da pesquisa demonstravam certas dificuldades para cursar a disciplina língua estrangeira moderna, nesse caso, o inglês. O estudo foi elaborado com o objetivo de examinar as percepções e o desempenho dos aprendizes no curso que enfoca o desenvolvimento da língua inglesa através da habilidade da leitura, usando gêneros discursivos. A pesquisa apresenta uma investigação sobre o impacto que o ensino baseado em gêneros tem nos aprendizes com estas características. De caráter reflexivo, o estudo busca esclarecer do que se trata o ensino que é voltado para turmas de EJA, especificamente no aprendizado de inglês, e defende a visão de que a abordagem baseada em gêneros discursivos é coerente com a realidade desse segmento do ensino público brasileiro.

\section{Palavras-chave}

Ensino e aprendizagem de inglês; gêneros discursivos; EJA - Educação de Jovens e Adultos; pesquisa-ação. 


\section{Abstract}

Maia, Mayara Alves; Hemais, Barbara Jane Wilcox (Advisor) . A reflexive investigation about a teaching-learning approach based on genres: the case of class 601. Rio de Janeiro, 2011. 97p. Dissertação de Mestrado - Departamento de Letras, Pontifícia Universidade Católica do Rio de Janeiro.

The aim of this research is to examine the performance of students in a foreign language course, when a change in the pedagogy was introduced, using a genre-based approach to teaching and learning. The students in the study were in the second grade of elementary education, in a "project" called EJA (Education for Teens and Adult Students) at a public school in the State of Rio de Janeiro, and, at the time when the research was conducted, they were experiencing various difficulties in studying English. This study was designed to examine these learners' perceptions of reading and their written production in a course in which the development of their language ability is focused on reading skills, through the exploration of genres. The study presents an investigation of the impact of genrebased teaching on learners with these characteristics. Using a reflective orientation, this study seeks to clarify the objectives of adult education classes, and it defends the view that the use of genres is consistent with the reality of this segment of Brazilian public education.

\section{Keywords}

Teaching and learning of English; genres; EJA - Education for Young and Adult Students; action research. 


\section{Sumário}

$\begin{array}{ll}\text { 1. Introdução } & 9\end{array}$

2. Ensino e aprendizagem de inglês 13

2.1 Educação para jovens e adultos 13

$\begin{array}{lll}2.1 .1 & \text { Os alunos } & 14\end{array}$

2.1.2 A sala de aula $\quad 15$

2.1.3 Observação, registro, avaliação e planejamento 16

2.1.4 O processo de aprendizagem dos alunos e professores 19

$2.2 \quad$ Uma visão reflexiva 20

2.2.1 Receptividade 22

2.2.1.1 Ansiedade $\quad 25$

$\begin{array}{lll}2.2 .1 .2 & \text { Autoestima } & 27\end{array}$

2.2.1.3 Motivação e reforço $\quad 28$

$3 \quad$ Gêneros discursivos 33

$4 \quad$ Metodologia $\quad 37$

$5 \quad$ Análise $\quad 40$

5.1 Depoimentos: professores e alunos $\quad 40$

$\begin{array}{lll}5.1 .1 & \text { Professores } & 40\end{array}$

$\begin{array}{lll}5.1 .2 & \text { Alunos } & 43\end{array}$

5.2 Gênero discursivo: formulário de emprego 44

5.3 Gênero discursivo: guia de instruções 52

5.4 Gênero discursivo: verbete/dicionário 58

$6 \quad$ Considerações finais $\quad 60$

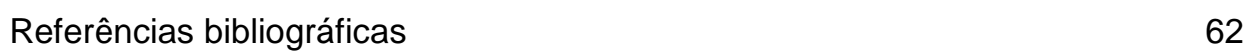

$\begin{array}{ll}\text { Anexos } & 66\end{array}$ 


\section{Índice de Anexos}

Anexo I: Questionário - professores

Anexo II: Relatórios de aula

Anexo III: Transcrição de áudio

Anexo IV: Textos usados nas aulas

Anexo V: Avaliações 